\title{
Cesarean Scar Pregnancy: A Case of Conservatively Managed Clinical Rarity
}

\author{
${ }^{1}$ Keeranmayee Mishra, ${ }^{2}$ Chirag Parikh, ${ }^{3}$ Malini Desai, ${ }^{4}$ Tushar Shah, ${ }^{5}$ Pallavi Ninama
}

\begin{abstract}
Background: Cesarean scar pregnancy is one of the rarest forms of ectopic pregnancy in which implantation occurs in the scar of a previous cesarean section. Due to increased incidence of cesarean section and first-trimester scan worldwide, more and more cases are diagnosed and reported nowadays.
\end{abstract}

Case report: A 25 years G3P2A0L2 patient with previous two LSCS was referred and admitted in an emergency with chief complaints of one and half months amenorrhea followed by bleeding per vaginum for 2 days preceded by intake of MTP pills 8 days back. Her general condition was fair. The patient was investigated with routine investigations, transvaginal ultrasound, Doppler and beta hCG. Ultrasonography (USG) and color Doppler findings were suggestive of cesarean scar pregnancy. Conservative management with methotrexate was done with strict follow-up. The GSAC completely resolved by 72 nd and day of diagnosis. Second look scopy at the time of tubal ligation reaffirmed the diagnosis and resolution of the scar pregnancy.

Keywords: Cesarean scar pregnancy, Ectopic, Methotrexate, Ultrasound.

How to cite this article: Mishra K, Parikh C, Desai M, Shah T, Ninama P. Caesarean Scar Pregnancy: A Case of Conservatively Managed Clinical Rarity J South Asian Feder Obst Gynae 2018;10(Suppl 1):358-360.

Source of support: Nil

Conflict of interest: None

Date of received: 1 December 2014

Date of acceptance: 14 January 2018

Date of publication: July 2019

\section{INTRODUCTION}

Cesarean scar pregnancy is one of the rarest forms of ectopic pregnancy. The first case of cesarean scar ectopic pregnancy was reported in 1978. It is an ectopic pregnancy implanted in the myometrium at the site of a previous cesarean section scar. Incidence varies between 1:1800 to 1:2226 during all last LSCS pregnancies according to recent case series. ${ }^{1}$ Mean gestational

\footnotetext{
${ }^{1}$ Postgraduate Student, ${ }^{2,4,5}$ Assistant Professor, ${ }^{3}$ Ex-Professor

${ }^{1-5}$ Department of Obstetrics and Gynaecology, BJ Medical College, Ahmedabad, Gujarat, India

Corresponding Author: Keeranmayee Mishra, Postgraduate Student, Department of Obstetrics and Gynaecology, BJ Medical College, Ahmedabad, Gujarat, India, e-mail: keeran.subham@ gmail.com
}

age at diagnosis is $7.5 \pm 2.5$ weeks. $^{2}$ It most commonly presents with light painless vaginal bleeding. Incidental finding during USG is the 2nd most common presentation. Early diagnosis with medical treatment with methotrexate is effective to cure the condition and evades the need for surgical evacuation and its complications.

\section{CASE DISCRIPTION}

A 25 years G3P2A0L2 patient was referred from outside hospital to our tertiary care center in an emergency with chief complaints of 1.5-month amenorrhea followed by bleeding $\mathrm{p} / \mathrm{v}$ since 2 days preceded by ingestion of MTP pills of her 8 days back. Her past menstrual history was regular, moderate and painless.

Her obstetric history revealed two previous lower segment cesarean sections with last childbirth 10 months back. Her past, personal and family history was nonsignificant. Her general condition was fair, and patient was conscious, cooperative, oriented, temperature-normal, pulse $-100 /$ minute, blood pressure $-120 / 80 \mathrm{~mm} \mathrm{Hg}$, respiratory rate- $20 / \mathrm{min}$, tongue, conjunctiva, nail were pink, sclera-white. On systemic examination, respiratory system and cardiovascular system auscultation were normal. On examination, the abdomen was soft, previous CS scar was present and healthy, on per speculum examination, spoting was present and on per vaginum examination uterus was retroverted, bulky and bilateral fornices were free.

\section{USG (TVS) on Day of Admission (Fig. 1)}

- Uterine cavity empty, ET-7.2 mm

- Cervical cavity-empty, cervical length $-2.5 \mathrm{~cm}$

- Internal os closed.

- Single G.sac with mean sac diameter-14 mm

- 6 weeks 2 days maturity

- Small fetal pole seen. CRL $3.5 \mathrm{~mm}-5$ weeks 5 days

- G.sac in cesarean scar area.

- Cardiac activity not appreciated

- No intervening myometrium between G.sac and bladder.

- Bulging was seen above the uterine surface in cesarean scar area (protruding G.sac)

- Chorionic plate was attached to the endometrial cavity 


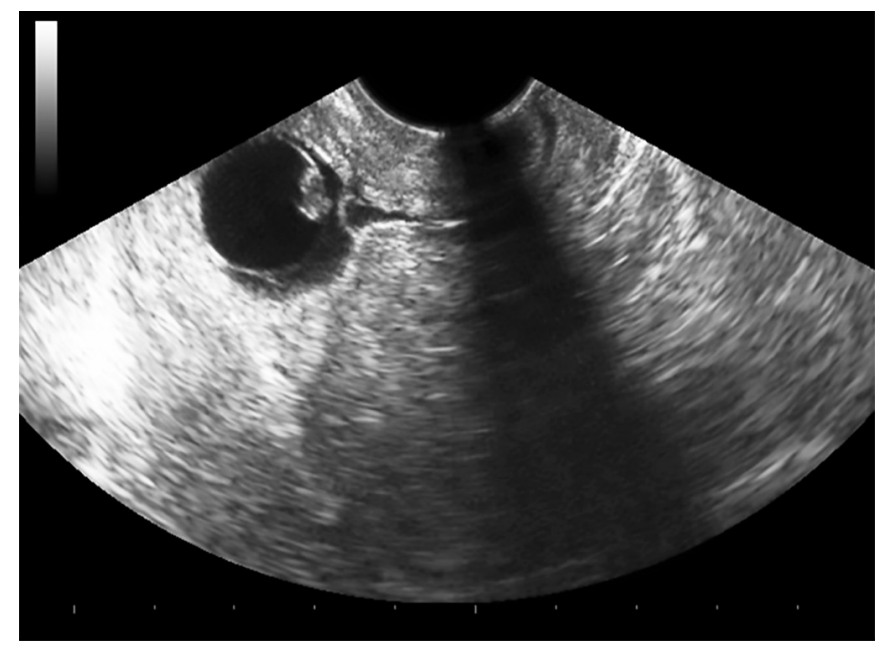

Fig. 1: G.sac at cesarean scar site

- No adnexal mass or free fluid in the pouch of Douglas. Color Doppler-vascularity was present around gestational sac (Fig. 2)

Serum $\beta$-hCG on the day of admission-10873.65 U/mL.

USG and color Doppler findings were suggestive of cesarean scar pregnancy.

Why we opted for medical management in our case? ${ }^{1}$

- The patient was hemodynamic and asymptomatic.

- Unruptured cesarean scar pregnancy <8 weeks.

- The myometrial thickness of $<2 \mathrm{~mm}$.

- $\mathrm{CBC}$ and LFT, RFT within normal limits.

\section{Management Protocol}

Injection methotrexate $(1 \mathrm{mg} / \mathrm{kg})$ intramuscular was given to the patient. Tablet cabergoline $0.5 \mathrm{mg} 2 \mathrm{tab}$ stat given (to prevent breast engorgement as breastfeeding was discontinued). Follow-up was done with repeated $\beta$-hCG and serial transvaginal sonography. Table 1

Table 1: Serial $\beta$-hCG, TVS findings post treatment with methotrexate

\begin{tabular}{|c|c|c|}
\hline$D O A$ & $\beta-h C G$ & TVS findings \\
\hline 19 & $11,165.83$ & $\begin{array}{l}\text { CRL } 6 \text { weeks } 4 \text { days, in cesarean } \\
\text { scar area. } \\
\text { CA ABSENT }\end{array}$ \\
\hline 24 & 5399 & G.sac $24 \times 15 \times 24 \mathrm{~mm}, \mathrm{CA}$ absent \\
\hline 30 & & $\begin{array}{l}\text { G.sac } 20 \times 17 \mathrm{~mm} \\
\text { CA absent }\end{array}$ \\
\hline 37 & & G.sac $22 \times 20 \mathrm{~mm}, \mathrm{CA}$ absent \\
\hline 44 & 209 & G.sac $21 \times 16 \mathrm{~mm}, \mathrm{CA}$ absent \\
\hline 53 & & G.sac $12 \times 9 \mathrm{~mm}, \mathrm{CA}$ absent \\
\hline 60 (Fig. 3) & & G.sac $8 \times 7 \mathrm{~mm}, \mathrm{CA}$ absent \\
\hline 72 (Fig. 4) & & $\begin{array}{l}\text { G.sac not seen } \\
\text { Septate mass } 1.9 \times 1.8 \mathrm{~cm}\end{array}$ \\
\hline 91 & & $\begin{array}{l}\text { Small organized irregular echogenic } \\
\text { structure in cesarean scar area } \\
\text { with no obvious vascularity on color } \\
\text { Doppler. }\end{array}$ \\
\hline 101 & 4 & No G.sac or any echogenic structure \\
\hline
\end{tabular}

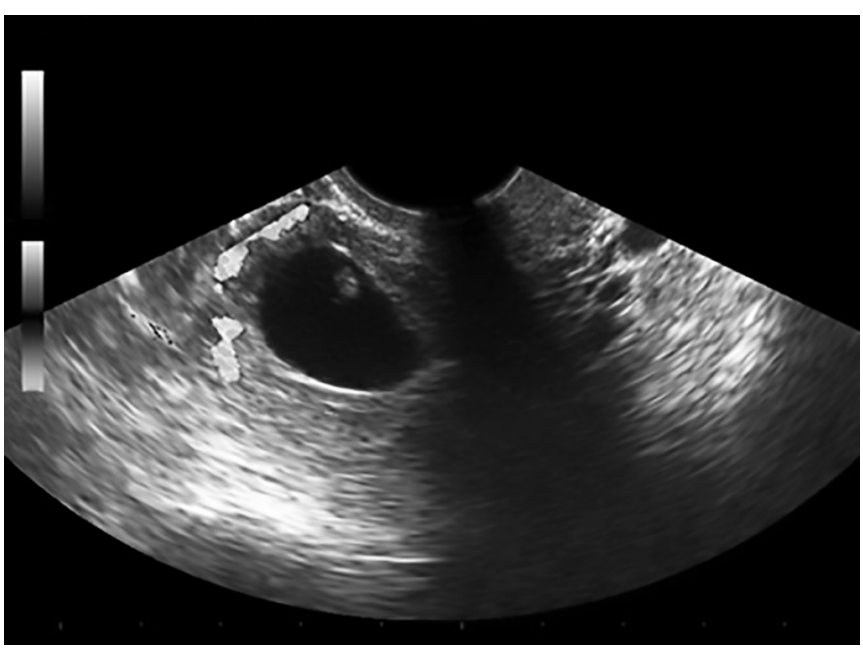

Fig. 2: Vascularity on color Doppler at site of implantation of G.sac at the scar site

shows serial $\beta$-hCG, TVS findings posttreatment with methotrexate

\section{On 16th Day of Admission}

The patient was taken for diagnostic laparoscopy as the patient was complaining of abdominal pain.

\section{PEROPERATIVE FINDINGS}

- Bladder adherent to the uterus and extremely vascular

- Omentum adherent to the anterior abdominal wall and cesarean scar area

- The highly vascular area seen at previous LSCS scar with bulging which indicated the site of implantation of G.sac at the scar which reaffirmed our diagnosis of scar pregnancy.

- Ultrasound pelvis was repeated on the same day, and it revealed the absence of cardiac activity.

Injection methotrexate $1 \mathrm{mg} / \mathrm{kg}$ intramuscular was repeated on the same day (16th DOA) as:

- The patient was hemodynamically stable and had no symptoms

- TVS showed absent cardiac activity and irregular G.sac with septations inside

- Serum $\beta$-hCG was falling

- There was no hemoperitoneum.

The patient was discharged on the 24th day of admission and advised for strict follow-up every week with $\beta$-hCG and serial TVS. Table 2 shows serial $\beta$-hCG, TVS findings in the follow-up period and after discharge.

The TVS findings on the 60th day of follow up showed a resolving G.sac with no cardiac activity (Fig. 3). Another follow-up scan revealed the G.sac to be converted to a septate mass (Fig. 4). On day 101 of the follow-up period, the G.sac had completely resolved and the patient was regularly followed up till she resumed her normal menses and laparoscopic tubal ligation was performed which 


\begin{tabular}{|c|c|c|}
\hline$D O A$ & $\beta-h C G$ & TVS findings \\
\hline 1 & 10873.65 & $\begin{array}{l}\text { G.sac means diameter } 14 \mathrm{~mm} \text { in } \\
\text { cesarean scar area. CA not appreciated, } \\
\text { no intervening myometrium between } \\
\text { G.sac and bladder }\end{array}$ \\
\hline 6 & $27,352.94$ & $\begin{array}{l}\text { G.sac mean diameter } 16 \mathrm{~mm} \text { in } \\
\text { cesarean scar area. CA present }\end{array}$ \\
\hline 8 & & $\begin{array}{l}\text { G.sac } 6 \text { weeks, in cesarean scar area, } \\
\text { CA present }\end{array}$ \\
\hline 11 & & $\begin{array}{l}\text { G.sac } 6 \text { weeks } 2 \text { days, in cesarean scar } \\
\text { area, CA present }\end{array}$ \\
\hline 16 & & $\begin{array}{l}\text { CRL } 6 \text { weeks } 4 \text { days, in the cesarean } \\
\text { scar area } \\
\text { CA absent }\end{array}$ \\
\hline
\end{tabular}

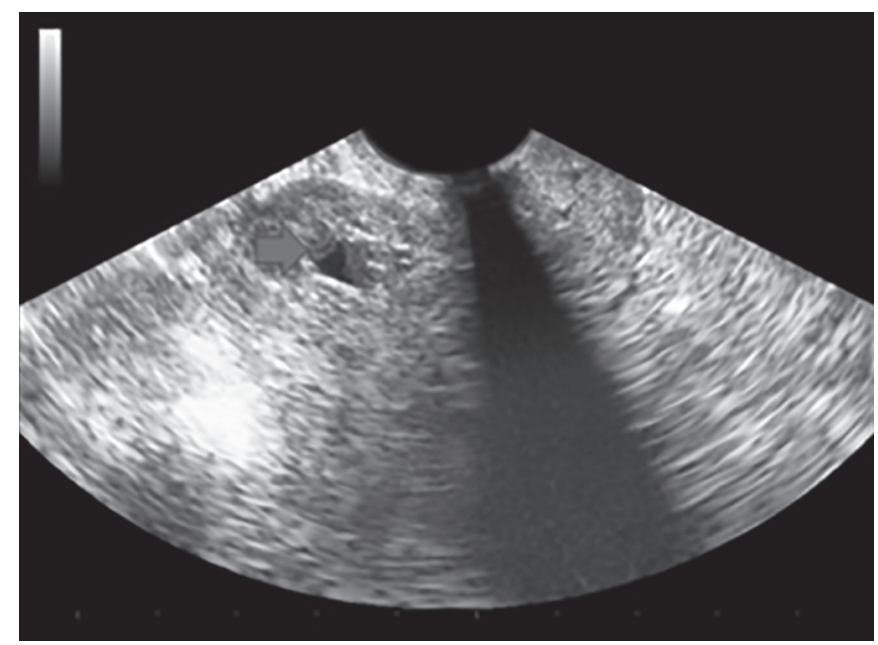

Fig. 3: Resolving G.sac after treatment with methotrexate

also served as a second look scopy and reaffirmed the resolution of the cesarean scar pregnancy.

\section{DISCUSSION}

Nearly $6.1 \%$ of all ectopic pregnancies in women who had at least one cesarean delivery is a cesarean scar pregnancy ${ }^{1}$ Severe acute pain with profuse bleeding implies impending rupture of a scar pregnancy.

Hemodynamic instability indicates ruptured scar pregnancy. Transvaginal ultrasound (TVS) is the primary diagnostic modality with a reported sensitivity of $84.6 \% .^{2}$ A sagittal view along the axis of the uterus through g.sac can localize a cesarean scar pregnancy with confidence.

Ultrasound criteria for the diagnosis of scar pregnancy ${ }^{1,2}$ are empty uterine cavity and cervical canal. Ges tational sac ( \pm fetal pole, \pm cardiac activity) in the anterior part of the uterine isthmus. Absence or defect in myo

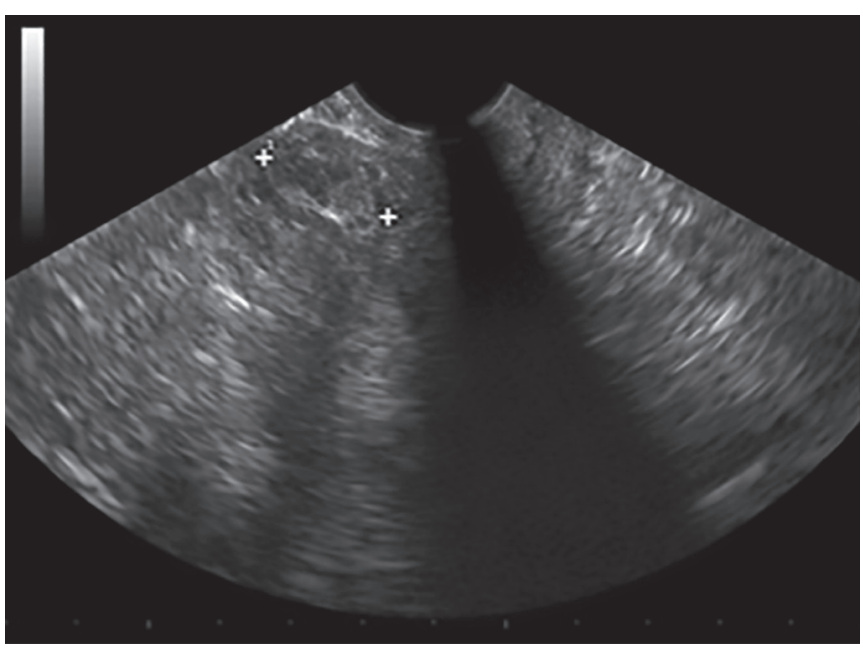

Fig. 4: Completely resolved G.sac post-treatment

metrial tissue between the bladder and the sac. No adnexal mass or free fluid in POD (implies unruptured state).

Other diagnostic modalities are color Doppler-distinct circular peritrophoblastic flow (circumferential vascularity), three-dimensional ultrasound, MRI, diagnostic hysteroscopy, diagnostic laproscopy.

Termination of pregnancy in the first trimester is preferred because of the high risk of subsequent uterine rupture conservative medical management includes the use of methotrexate, local injection of embryoids (USG guided) like methotrexate, potassium chloride, hyperosmolar glucose. Other treatment options include combination medical treatment, medical treatment with surgical sac aspiration, uterine curettage if sac implantation is more towards the uterine cavity, selective uterine artery embolization, hysteroscopic evacuation, laparoscopic removal, primary open surgical treatment and hysterectomy ${ }^{1-3}$ as the last resort.

Complications like scar rupture can lead to obstetric hysterectomy and mortality. Because of the rarity of the condition, the experience is based mainly on case series and, i.e., level III evidence. ${ }^{4}$

\section{REFERENCES}

1. Ash A, Smith A, et al. Caesarean scar pregnancy. BJOG Int J Obstetr Gynaecol 2007;114(3):253-263.

2. Rotas MA, Haberman S, et al. Cesarean scar ectopic pregnancies: etiology, diagnosis, and management. Obstetr Gynecol 2006;107(6):1373-1381.

3. Little EA, Moussavian B, et al. Cesarean delivery scar ectopic pregnancy. Ultrasound Quarterly 2010;26(2):107-109.

4. Burns PB, Rohrich RJ, et al. The levels of evidence and their role in evidence-based medicine. Plastic and Reconstructive Surgery 2011;128(1):305-310. 